\title{
DIREITO E LINGUAGEM: GRAMÁTICA JURÍDICA E INSTRUMENTALIDADE PROCESSUAL
}

\author{
José Antonio Callegari ${ }^{1}$
}

Universidade Federal Fluminense - UFF. PPGSD

calegantonio@yahoo.com.br

\section{Resumo}

Nesse artigo, analisamos o processo como um texto, formado a partir de relações humanas em contextos institucionais. Seguindo uma ordem discursiva programada (Código de Processo) as partes e o juiz interagem produzindo discursos jurídicos que formam uma unidade discursiva. O Código é visto como uma gramática jurídica ordenando os atos de fala na jurisdição. O texto propõe uma releitura do processo onde a técnica jurídica não deve se sobrepor às relações humanas que formam o seu conteúdo.

Palavras-chave: Processo. Gramática jurídica. Instrumentalidade discursiva.

\section{RIGHT AND LANGUAGE: LEGAL GRAMMAR AND PROCEDURAL INSTRUMENTALITY}

\begin{abstract}
In this article, we analyze the process as a text, formed from human relations in institutional contexts. Following a programmed discursive order (Process Code) the parties and the judge interact producing legal discourses that form a discursive unit. The Code is seen as a legal grammar ordering speech acts in the jurisdiction. The text proposes a re-reading of the process where the legal technique should not overlap the human relations that form its content.
\end{abstract}

Keywords: Process. Legal Grammar. Discursive Instrumentality.

\section{INTRODUÇÃO}

Nesse artigo, analisamos o processo judicial como um texto. Para desenvolver o argumento, adotamos o Código de Processo como gramática jurídica que orienta as práticas discursivas das partes e do juiz.

\footnotetext{
${ }^{1}$ José Antonio Callegari. Doutor em ciências jurídicas e sociais. Universidade Federal Fluminense. PPGSD. Artigo extraído e adaptado de nossa tese de doutorado intitulada HERMENÊUTICA PROCESSUAL: análise tridimensional do processo.
} 
No contexto de acesso à Justiça (CAPELLETI; GARTH, 1988), é possível analisar o processo não mais como instrumento técnico sob o domínio restrito de juristas e de outros profissionais da área. Assim sendo, o processo judicial democrático se apresenta como instrumento discursivo/dialógico de aplicação do Direito.

Ao eleger a dignidade da pessoa humana como princípio fundamental, a Constituição Federal prescreve novos meios de operacionalizar o direito, dentre eles a proximidade discursiva/dialógica entre as partes e o juiz.

Numa relação tridimensional, autor, réu e juiz produzam textos parciais segundo uma ordem sintática, semântica e pragmática, que lhes permite narrar fatos, valorar condutas e produzir a sentença como norma jurídica compartilhada entre eles e ato de encerramento dessa cadeia discursiva.

Com essas observações, o artigo pretende despertar o interesse daqueles que desejam práticas judiciárias comprometidas com o diálogo social. Tratando o processo como instrumento discursivo/dialógico, podemos democratizar a aplicação do Direito, rompendo com dogmas formalistas que dificultam o acesso à Justiça.

\section{GRAMÁTICA JURÍDICA}

Analisando o Código de Processo, notamos certa aproximação entre a Gramática Jurídica (GREIMAS, 1976) e a Teoria Tridimensional do Direito (REALE, 1994). A partir dessa gramática, o processo se constitui como ato de linguagem tridimensional.

Nele, os integrantes da relação processual (autor, réu e juiz) articulam fatos, valores e normas segundo a estrutura linguística desse Código normativo (sintaxe, semântica e pragmática). Observando o Código de Processo Civil, por exemplo, identificamos padrões tridimensionais de interação discursiva: 


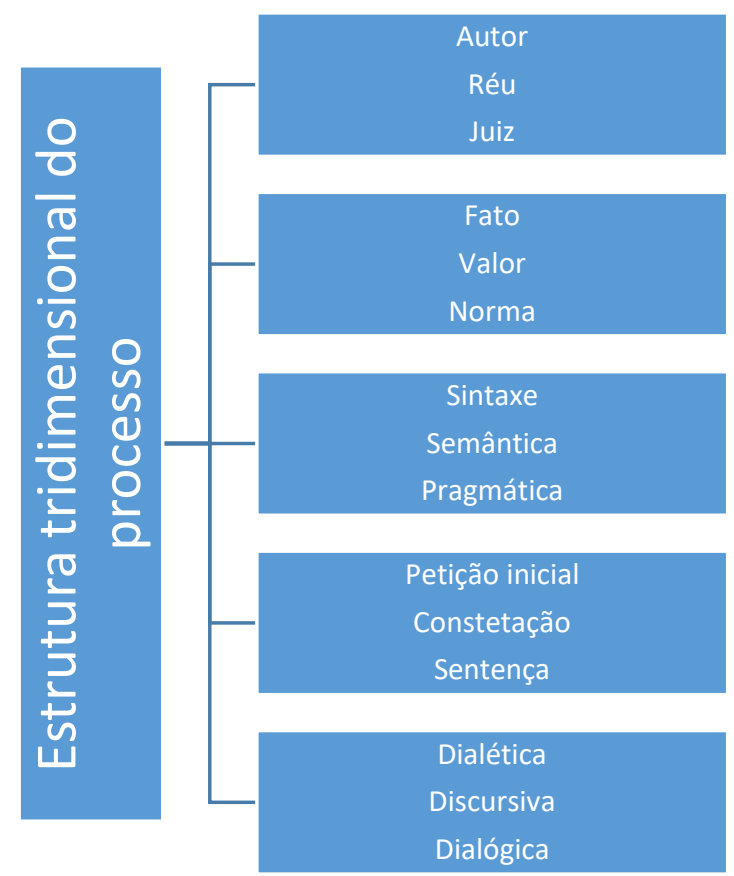

O processo, desse modo, vai se constituindo por atos de fala na jurisdição, praticados por atores sociais, tais como: autor, céu, juiz, advogados, testemunhas, servidores, peritos, etc. Cada qual segue a ordem do discurso estabelecida previamente pelo Código de Processo (gramática jurídica). Nessa estrutura, destaca-se o papel ativo do produtor textual:

Como se pode perceber no desenvolvimento da discussão empreendida, a percepção biológica (estágio pré-código) é o primeiro passo para o percurso gerativo de qualquer discurso, e já nessa fase se manifesta a criatividade humana na formação do sentido, pois, antes de ser agente passivo, o ser racional é agente ativo do processo de formação da significação. Toda semiótica se articula sobre um universo de experiência que se pode chamar de "referente" (designatum), este que é fruto de uma interação do homem com os ambientes natural, social, cultural, físico, político, econômico...que o rodeiam. (BITTAR, 2015. Pg. 96).

O percurso gerativo, assim imaginado, opera segundo um "esquema de funcionamento" (BITTAR, 20015), aqui representado pelo Código de Processo. Como esquema de ação ou programação discursiva, o Código estabelece a ordem do discurso, definindo os parâmetros de textualização, tais como requisitos e pressupostos processuais. Em sua função instrumental, o Código disciplina os atos de fala na jurisdição em conformidade com a técnica textual do Direito. Tudo nele converge para a formação sentidos jurídicos:

A textualização, de fato, como manifestação do discurso, pressupõe a profundidade das relações sensoriais, perceptivas, semiológicas, lógicas... e sua ocorrência nada mais representa que a atualização de esquemas narrativos. Todo texto se produz valendo-se dessas categorias comungadas, e manifesta representações, percepções, leituras, interesses, vontades, intenções, pertinentes a situações determinadas, universos de discurso determinados, a contextos culturais próprios, a sujeitos históricos. (BITTAR, 2015. Pg. 98-99). 
O esquema tridimensional proposto permite observar a formação complexa do processo como instrumento discursivo/dialógico de aplicação do direito. Percebe-se, com isso, um encadeamento de enunciados parciais que se sucedem no tempo em fases processuais bem definidas.

A sucessão de atos de fala na jurisdição, desse modo, segue a ordem do discurso processual gramaticada. Nessa sequência, a petição inicial, a contestação e a sentença formam o eixo discursivo principal do processo ${ }^{2}$.

Tais atos de fala textualizam a trama processual, segundo a estrutura sintática semântica e pragmática codificada. Desse modo, a tessitura coerente e coesa do processo, mediante sequências discursivas bem ordenadas, pode contribuir para a segurança jurídica do autor e do réu, servindo como meio de controle social dos atos processuais.

Por este ângulo, o texto processual é o resultado de interações humanas que se manifestam em contexto institucionais. Nesse aspecto, ele contém pretensões que demandam uma atuação jurisdicional adequada, sugerindo uma releitura do conceito de relação jurídica processual. Assim:

O conceito de relação jurídica, dado o seu caráter geral-abstrato, neutraliza a substancia da própria relação em vida. A teoria de Büllow, ao sistematizar uma relação jurídica processual, não escapou do conceitualismo ou do cientificismo neutro próprios à pandectística.

A teoria da relação jurídica processual, se é capaz de demonstrar o que acontece quando o litigante vai em busca do juiz em face daquele que resiste à sua pretensão, encobre intenções do Estado ou de quem exerce o poder, além de ignorar as necessidades das partes, assim como as situações de direito material e as diferentes realidades dos casos concretos.

A pretensa neutralidade do conceito de relação jurídica processual certamente escamoteou a realidade concreta, permitindo a construção de uma ciência processual que se queria bastante ou supunha que poderia viver em si mesma, sem olhar para a

\footnotetext{
${ }^{2}$ Existem situações nas quais o processo avança sem a contestação do réu. Desde que observados certos requisitos legais, a saber:

Art. 249. A citação será feita por meio de oficial de justiça nas hipóteses previstas neste Código ou em lei, ou quando frustrada a citação pelo correio.

Art. 250. O mandado que o oficial de justiça tiver de cumprir conterá:

I - os nomes do autor e do citando e seus respectivos domicílios ou residências;

II - a finalidade da citação, com todas as especificações constantes da petição inicial, bem como a menção do prazo para contestar, sob pena de revelia, ou para embargar a execução;

Art. 344. Se o réu não contestar a ação, será considerado

Art. 345. A revelia não produz o efeito mencionado no art. 344 se:

I - havendo pluralidade de réus, algum deles contestar a ação;

II - o litígio versar sobre direitos indisponíveis;

III - a petição inicial não estiver acompanhada de instrumento que a lei considere indispensável à prova do ato;

IV - as alegações de fato formuladas pelo autor forem inverossímeis ou estiverem em contradição com prova constante dos autos.

Art. 348. Se o réu não contestar a ação, o juiz, verificando a inocorrência do efeito da revelia previsto no art. 344, ordenará que o autor especifique as provas que pretenda produzir, se ainda não as tiver indicado.

http://www.planalto.gov.br/ccivil_03/_Ato2015-2018/2015/Lei/L13105.htm
} 
realidade do direito material e para a vida das pessoas de carne e osso. (MARINONI; ARENHART; MITIDIERO. 2017. Pg. 437-438).

Num cenário efetivação de direitos humanos, conjugam-se duas gramáticas jurídicas que se complementam ao disciplinar os vários aspectos das relações humanas. A primeira, estabelece o dever ser no mundo da vida e a segunda estabelece o dever ser no exercício da jurisdição.

Ambas ordenam as performances discursivas das pessoas em relações jurídicas determinadas. No primeiro caso, temos a Constituição, o Código Civil, o Código Penal e a Consolidação das Leis do Trabalho, etc., regendo as relações jurídicas no mundo da vida. No segundo, temos o Código de Processo Civil, o Código de Processo Penal e o Processo do Trabalho, regulando as relações processuais em função de conflitos decorrentes das relações reguladas pelo direito material respectivo.

Num sentido prático, quando surgem controvérsias e desentendimentos, não superados por meios alternativos de resolução de conflitos (mediação, conciliação e arbitragem). os envolvidos levam suas pretensões ao Poder Judiciário ${ }^{3}$. Nesse momento, o Código de Processo é acionado como referente normativo que ordena os atos de fala na jurisdição.

No processo, as partes e o juiz elaboram textos jurídicos com base na gramática processual, sintonizada com a gramática jurídica do direito material correspondente ${ }^{4}$. Havendo um crime, por exemplo, os sujeitos do processo utilizam a Constituição, o Código Penal e outras normas jurídicas como referência discursiva, ordenando os atos de fala segundo as regras do Código de Processo Penal ${ }^{5}$.

\footnotetext{
3 "Ora, assumindo que o sistema processual é impulsionado por uma série de escopos e que o Estado chama a si a atribuição de propiciar a consecução destes (supra, n. 5), uma das funções estatais é a de realizar os escopos do processo. Tal é a jurisdição estatal, função exercida pelo Estado através dos juízes com vista à solução imperativa de conflitos interindividuais ou supraindividuais e aos demais escopos do sistema processual. Entre estes está o de atuação do direito material, tradicionalmente apontado como fator apto a dar à jurisdição uma feição própria e diferenciá-la conceitualmente das demais funções estatais - pois nenhuma outra é exercida com o objetivo de ar efetividade ao direito material em casos concretos. Conceitua-se, pois a jurisdição estatal, a partir dessas premissas, como função do Estado, destinada à solução imperativa de conflitos e exercida mediante a atuação da vontade do direito em casos concretos. " (DINAMARCO; LOPES. 2016. Pg. 77, 78)

${ }^{4}$ Por muito tempo, a relação entre as regras prescritas nos Códigos (Civil e Penal) eram conhecidas como como normas substantivas; enquanto aos Códigos de Processo (Civil e Penal) eram tratados como normas adjetivas. Esta visão dogmática está superada. Mas, há um que de verdade. Entre as normas de conduta e as normas processuais existe uma relação de aproximação semântica fundamental. Não se resolve uma questão penal adotando-se o Processo Civil. O Processo Penal cuida dos crimes tipificados no Código Penal e outras normas penais extravagantes (prescritas em leis específicas). Daí, decorre também uma visão instrumental do processo. Mas essa instrumentalidade gramatical ou técnica é insuficiente, se, através dela, não observarmos a instrumentalidade dialética, discursiva e dialógica do processo.

${ }^{5} \mathrm{O}$ Código de Processo Civil permite a aplicação de suas regras gramaticais nos processos eleitoral, trabalhista e administrativo, nestes casos:
} 
Note-se, pois, que o processo é um texto formado em um contexto social e institucional delimitado por gramáticas jurídicas que se complementam. Assim, cada relação jurídica no mundo da vida, regida por normas de direito material, compõe o cenário das narrativas levadas o processo, sob a regência da respectiva gramática processual.

A relação biunívoca entre as gramáticas de direito material e a gramática processual serve de estrutura para o desenvolvimento tridimensional do processo. Assim, autor, réu e juiz praticam atos processuais numa sequência dialética, discursiva e dialógica, segundo normas de regência sintática, semântica e pragmática, enunciando pretensões em torno de fatos, valores e normas. Estrutura e conteúdo sem integram no processo.

\section{INSTRUMENTALIDADE DISCURSIVA: ASPECTOS TRIDIMENSIONAIS}

Em termos de performance, já dissemos que o processo contém um eixo discursivo principal, no qual articulam-se as falas do autor, do réu e do juiz. Em face da perspectiva tridimensional por nós adotada, observamos a relação processual como um triângulo ${ }^{6}$, pois o autor inicia o processo, através da petição inicial, o réu defende-se através da contestação e outros meios técnicos de impugnação, e o juiz decide as questões através da sentença, como ato discursivo final do processo. Assim, temos:

Art. 15. Na ausência de normas que regulem processos eleitorais, trabalhistas ou administrativos, as
disposições deste Código lhes serão aplicadas supletiva e subsidiariamente.
http://www.planalto.gov.br/ccivil 03/ Ato2015-2018/2015/Lei/L13105.htm

A Consolidação das leis do Trabalho, igualmente permite a aplicação do CPC como gramática processual supletiva:

Art. 769 - Nos casos omissos, o direito processual comum será fonte subsidiária do direito processual do trabalho, exceto naquilo em que for incompatível com as normas deste Título. https://www.planalto.gov.br/ccivil_03/decreto-lei/Del5452.htm

\footnotetext{
6 "Não há acordo na doutrina quanto à configuração da relação jurídica processual. Em sua formulação originária, a teoria desta a apresentava como uma figura triangular, afirmando que há posições jurídicas processuais que interligam autor e Estado, Estado e réu, réu a autor. Outros houve, que lhe deram configuração angular, dizendo que há posições jurídicas processuais ligando autor e Estado e, de outra parte, Estado e réu; esses autores negam que haja contato direto entre autor e réu. Na doutrina brasileira predomina a ideia da figura triangular, sendo argumentos dos autores que a sustentam: a) as partes têm o dever de lealdade recíproca; b) a parte vencida tem a obrigação de reembolsar à vencedora as custas despendidas; c) podem as partes convencionar entre si a suspensão do processo (CPC, art. 26, II). Todos esses argumentos recebem impugnação dos seguidores da teoria angularista, mas a verdade é que não há grande interesse, nem prático nem teórico, na solução da disputa. O importante, e isso é pacífico é que a relação jurídica processual tem uma configuração tríplice (Estado, autor e réu). " (CINTRA; GRINOVER; DINAMARCO. 1994. Pg. 287, 288).
} 


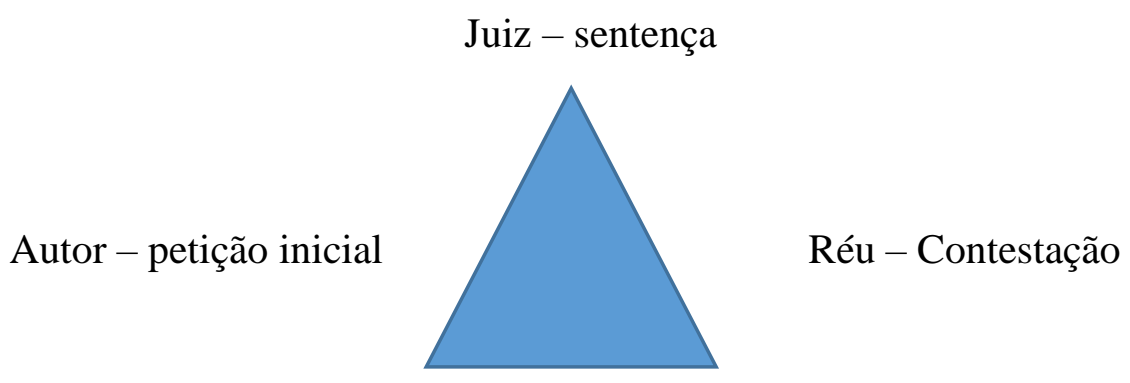

Mas, a relação discursiva não é tão simples assim, linear e bem definida. Entre as falas principais, articulam-se outras coadjuvantes. Ao eixo discursivo principal, somam-se outros com objetivos e funções gramaticais variadas. São discursos produzidos pelos procuradores das partes, representantes, litisconsortes ${ }^{7}$, terceiros intervenientes, escrivãs, chefes de secretarias, peritos, conciliadores, mediadores, testemunhas, etc. Cada discurso assim proferido integra uma trama polifônica, previamente ordenada pela gramática processual.

Em sua função gramatical, o Código de Processo ordena os atos de fala na jurisdição, estabelecendo as condições de desenvolvimento válido e regular do processo. Define os papéis de cada interlocutor, seus deveres, direitos e ônus, bem como a forma, o tempo e o modo dos atos processuais, etc.

Resumindo, o Código estrutura as condições de formação e desenvolvimento dialético, discursivo e dialógico do processo. Em sua dimensão técnica, não deve neutralizar a dimensão sociolinguística da interação que se estabelece entre pessoas, pois em cada uma delas, antes do conflito jurídico, há uma luta por reconhecimento de cidadania e dignidade existencial de viés hegeliano.

Como vimos, a gramática processual organiza os frames discursivos do processo. Nesse sentido, o Código de Processo Civil constitui a unidade do processo a partir da articulação coerente de unidades discursivas menores:

Esse sistema foi mantido no novo Código de Processo Civil, que contém, um
procedimento-padrão, de aplicabilidade geral a todas as causas para as quais não seja
determinada a aplicação de algum outro (CPC, art. 318$)^{8}$ e que é apto a proporcionar
o reconhecimento, o dimensionamento, a preservação e a satisfação de uma

\footnotetext{
${ }^{7}$ Art. 113. Duas ou mais pessoas podem litigar, no mesmo processo, em conjunto, ativa ou passivamente, quando: I - entre elas houver comunhão de direitos ou de obrigações relativamente à lide;

II - entre as causas houver conexão pelo pedido ou pela causa de pedir; III - ocorrer afinidade de questões por ponto comum de fato ou de direito.

${ }^{8}$ Art. 318. Aplica-se a todas as causas o procedimento comum, salvo disposição em contrário deste Código ou de lei.

Parágrafo único. O procedimento comum aplica-se subsidiariamente aos demais procedimentos especiais e ao processo de execução. http://www.planalto.gov.br/ccivil_03/_Ato2015-2018/2015/Lei/L13105.htm
} 
pretensão. Esse procedimento é dividido em fases, que podem comportar a divisão em subfases, a seguir descritas.

A primeira fase desse procedimento complexo e sincrético é a fase de conhecimento, que tem por objetivo preparar e produzir julgamentos de mérito e é a que mais se presta à divisão em subfases, nas quais o legislador procura, na medida do possível, agrupar os atos que compõem o procedimento. Essas subfases são a postulatória, a ordinatória, a instrutória e a decisória. (DINAMARCO; LOPES. 2016. Pg. 130).

Assim, no Processo Civil, podemos identificar três fases ou frames processuais: postulatória ${ }^{9}$, instrutória ${ }^{10}$ e decisória ${ }^{11}$. Na primeira, autor e réu narram os fatos, argumentam e deduzem suas pretensões (acusação e defesa). Na segunda, eles produzem as provas, visando convencer o juiz. Na terceira, o juiz narra as ocorrências do processo e decide com base no material probatório ${ }^{12}$ existente nos autos, demonstrando racionalmente os fundamentos de sua decisão. Assim, cada frame conecta-se ao seguinte, formando uma unidade discursiva maior: o processo.

No sentido gramatical, o Código de Processo estabelece a ordem do discurso jurídico. Observando a sintaxe processual, os sujeitos praticam atos de fala, conferindo sentido aos seus enunciados (semântica). Entre a norma gramatical e o texto produzido há um espaço discursivo

\footnotetext{
9 "Fase postulatória é aquela em que as partes postulam, ou seja, em que elas apresentam suas pretensões contrapostas. É nessa fase que se formulam demandas, fazem-se as citações, há a tentativa de conciliação e tem o réu a oportunidade para oferecer sua contestação, que é o primeiro de seus atos de defesa a serem praticados no processo." (DINAMARCO; LOPES. 2016. Pg. 131)

10 “A fase instrutória principia quando o processo é saneado e consiste na realização de provas e oferecimento das alegações finais pelas partes. Muito embora a instrução probatória não preencha toda a fase instrutória, é nela que se concentram as maiores atenções e as atividades mais intensas do juiz e dos litigantes. ". (DINAMARCO; LOPES. 2016. Pg. 133)

11 "Realizada a prova e apresentadas as alegações finais pelas partes, tem início a fase decisória, com a prolação da sentença. Pode também acontecer que, por não se julgar suficientemente instruído, o juiz peça ainda alguns esclarecimentos às partes, mande intimar novas testemunhas ou mesmo determine a realização de segunda perícia (art. 480). " (DINAMARCO; LOPES. 2016. Pg. 134)

${ }^{12}$ A respeito do exame das provas, aplica-se o princípio da unidade da prova:

TST - AGRAVO DE INSTRUMENTO EM RECURSO DE REVISTA AIRR 29633 29633/2002-902-02-00.5 (TST)

Data de publicação: 27/11/2009

Ementa: AGRAVO DE INSTRUMENTO. ESTABILIDADE SINDICAL. LIMITES DA LIDE. NULIDADE DO ACÓRDÃO. INOCORRÊNCIA. NÃO PROVIMENTO. Após a análise do conjunto fático-probatório dos autos (princípio da unidade da prova), ainda que não impugnado determinado fato constitutivo do direito do autor, pode o órgão julgador, com base em seu livre convencimento motivado, concluir pela inviabilidade da pretensão, conforme preceituado no artigo 131 do CPC. Agravo de instrumento a que se nega provimento. http://www.jusbrasil.com.br/topicos/2167555/principio-da-unidade-da-prova

TRT-22 - RECURSO ORDINÁRIO RO 1050200900222003 PI 01050-2009-002-22-00-3 (TRT-22)

Data de publicação: 19/03/2010

Ementa: INOVAÇÃO RECURSAL. VEDAÇÃO. NÃO CONHECIMENTO. Não se conhece de matéria arguida somente nas razões recursais, por se tratar de inovação à lide, prática vedada pelo ordenamento jurídico (art. 460 do CPC ). VALORAÇÃO DA PROVA. NULIDADE DO JULGADO. NÃO CONFIGURAÇÃO. A decisão que analisa o conjunto probatório para, ao final, concluir pela improcedência do pedido objeto da ação, não se atendo a determinada prova não pode, por isso, ser declarada nula, porquanto nenhuma prova serve sozinha para evidenciar a satisfação de um direito ou o cumprimento de uma obrigação, já que a sua valoração deve ser feita em confronto com os demais elementos existentes nos autos (princípio da unidade da prova). PROVA TESTEMUNHAL INCONSISTENTE. SUPERIORIDADE DA PROVA DOCUMENTAL. HORAS EXTRAS INDEVIDAS. Deve prevalecer a prova documental, quando a prova testemunhal é insuficiente para afastá-la. Indevido, portanto, o pedido de condenação em horas extras. http://www.jusbrasil.com.br/topicos/2167555/principio-da-unidade-da-prova
} 
real, onde se intercalam atos de fala e interações face a face; e o lugar por excelência dessas interações é a audiência de instrução e julgamento.

A estrutura tridimensional do processo permite concluir que:

\begin{abstract}
No contexto das reflexões empreendidas por meio deste texto, há que se dizer, ademais, que se estará a considerar a triangularidade das relações semióticas (semântica/pragmática/sintática) como pressuposto de conhecimento e de referência de central importância. A recorrência a esse espectro do problema, portanto, far-se-á constante durante todo o percurso do texto.

Se a Semiótica Jurídica cabe estudar a significação, então, é claro, desse seu espectro de investigação não cabe alhear o triângulo semiótico (modelo formal de Morris e Carnap, inspirado em Peirce, reafirmado, posteriormente, por Ogden \& Richards), pois o triângulo semiótico representa a totalidade do fenômeno do sentido, seja com relação ao sujeito (conceito, interpretante), seja como relação ao referente (psicológico, lógico, físico, metafísico), seja com relação ao significante (simbologia, linguagem, sistema de representação). Semântica jurídica, sintática jurídica e pragmática jurídica são os três grandes ramos da Semiótica Jurídica, nesse sentido. (BITTAR, 2015. Pg. 70).
\end{abstract}

Como destacamos, os atos de fala integram uma cadeia discursiva dialética, discursiva e dialógica, segundo as três dimensões gramaticais do processo (sintaxe, semântica e pragmática). Tais atos, proferidos pelas partes, advogados, juiz e auxiliares da justiça, dentre outros, mediante turnos de fala e interações face a face, formam discursos situacionais, tematizando determinada realidade social em torno de fatos, valores e normas:

A noção de circunstancialidade é fundamental para compreensão do fenômeno histórico que subjaz à existência do discurso, pois o discurso sempre ocorre no tempo e na história; tal apontamento de desprende como consequência relevante para uma semiótica discursiva, que não se quer neutra, mas sim crítica das produções fenomênicas de discurso. O discurso, portanto, é sempre um discurso situacional, vivendo em constante dialética com as condições de sua produção, com os valores e os demais importes fáticos que relevam de uma fenomênica discursiva, de um contexto de produção em que se acentua o estar em discurso. (BITTAR, 2015. Pg. 92).

Relembrando, o processo tem início com a petição inicial, provocando as falas do réu (contestação) e do juiz (sentença). De tal modo, os atos de fala sucedem-se no tempo em uma relação causal. Via de regra, um ato é causa do que lhe segue, gerando e mantendo o percurso gerativo do texto processual num ritmo cadenciado segundo o procedimento adotado pela gramática processual. Por essa razão, rupturas discursivas ${ }^{13}$ podem gerar nulidades processuais,

${ }^{13}$ O Código de Processo Civil admite certas rupturas discursivas, sem prejuízo da progressão textual: revelia do réu e preclusão para se manifestar nos autos, por exemplo. No primeiro caso, o réu não se defende quando citado regularmente. No segundo caso, uma das partes deixa de praticar um ato processual no prazo determinado. Quando previstas, segundo o princípio da legalidade, estas rupturas ou lacunas discursivas fazem parte da ordem do discurso processual. São casos excepcionais cuja aplicação requer cuidado e ponderação. No caso da revelia observe-se que:

Art. 344. Se o réu não contestar a ação, será considerado revel e presumir-se-ão verdadeiras as alegações de fato formuladas pelo autor.

Art. 345. A revelia não produz o efeito mencionado no art. 344 se:

I - havendo pluralidade de réus, algum deles contestar a ação; 
uma vez que perturbam a coerência sintática, semântica e pragmática do processo, bem como o seu desenvolvimento válido e regular.

Rupturas dessa ordem comprometem a segurança jurídica das partes, contaminando a unidade discursiva do processo, pois:

\begin{abstract}
A nulidade de um ato processual pode propagar-se a outros atos, em si sadios, mediante um processo de contaminação capaz de comprometer até mesmo o procedimento inteiro, conforme o caso. O Código de Processo Civil estatui, mediante uma disposição bastante ampla, que, "anulado o ato, consideram-se de nenhum efeito todos os subsequentes que dele dependam". No entanto, o mesmo dispositivo ressalva que "a nulidade de uma parte do ato não prejudicará as outras que dela sejam independentes" (art. 281). Para a correta identificação dos atos que ficam contaminados pela nulidade de um ato anterior, o art. 282 do Código de Processo Civil dispõe que, "ao pronunciar a nulidade, o juiz declarará que atos são atingidos e ordenará as providências necessárias a fim de que sejam repetidos ou retificados". (DINAMARCO; LOPES. 2016. Pg. 194).
\end{abstract}

Por certo, os atos de fala na jurisdição seguem uma lógica relacional e referencial. A petição inicial provoca a jurisdição, inaugurando a relação processual e trazendo o réu ao processo. Nesse sentido, ela se manifesta como a primeira referência discursiva do réu (contestação) que dela retira elementos para sua defesa em contraditório. Petição inicial e contestação, dentre outras manifestações presentes nos autos, são referências discursivas para a formação do convencimento judicial e fundamentação da sentença ${ }^{14}$.

Assim, o processo se desenvolve rumo ao provimento final: sentença. Entre a petição inicial e a manifestação final do juiz, sucedem-se inúmeros atos discursivos: a resposta do réu, os depoimentos, os atos dos auxiliares da justiça, etc. Todos formam uma trama textual, formando uma unidade discursiva coesa e coerente.

II - o litígio versar sobre direitos indisponíveis;

III - a petição inicial não estiver acompanhada de instrumento que a lei considere indispensável à prova do ato;

IV - as alegações de fato formuladas pelo autor forem inverossímeis ou estiverem em contradição com prova constante dos autos.

Art. 346. Os prazos contra o revel que não tenha patrono nos autos fluirão da data de publicação do ato decisório no órgão oficial.

Parágrafo único. O revel poderá intervir no processo em qualquer fase, recebendo-o no estado em que se encontrar. http://www.planalto.gov.br/ccivil_03/_Ato20152018/2015/Lei/L13105.htm

\footnotetext{
${ }^{14}$ Mais uma vez registramos que nem toda relação processual conta com a defesa e a contestação do réu, pois em casos de revelia o processo segue adiante até a decisão final do juiz. Salvo nos casos de direitos indisponíveis, cujo tratamento processual diferenciado não cabe analisar nesse momento.
} 


\title{
4 CONSIDERAÇÕES FINAIS
}

Ao percebermos o esquema tridimensional do processo, podemos despertar interesses por uma análise crítica e atualizada desse instrumento jurídico e, até mesmo, da metodologia de estudo e de ensino processual, pois:

\begin{abstract}
A dogmática jurídica trabalhada nas salas de aula (e reproduzida em boa parte dos manuais e compêndios) considera o Direito como sendo uma mera racionalidade instrumental. De um modo ou de outro, a regra máxima é a "simplificação do Direito". Em termos metodológicos, predomina o dedutivismo, a partir da reprodução inconsciente da metafísica relação sujeito-objeto. Nesse contexto, o próprio ensino jurídico é encarado como uma terceira coisa, no interior da qual o professor é um outsider do sistema. [...]

A hermenêutica praticada nas salas de aula continua absolutamente refratária ao giro linguístico (linguistic turn); em regra, continua-se a estudar os métodos tradicionais de interpretação (gramatical, teleológico, etc.), como se o processo de interpretação pudesse ser feito em partes ou fatias. (STRECK. 2014. Pg. 99).
\end{abstract}

A tensão entre norma e prática social lança um desafio epistemológico: a construção de um saber jurídico a partir da realidade vivida no processo. A construção de uma epistemologia do processo talvez seja o grande desafio atual. Numa cultura afogada em leis, percebemos a realidade social enviesada, neutralizando, quando não anulando, as falas e as expectativas das pessoas.

Consciente ou não, parcela do mundo jurídico oprime e suprime a cidadania quando não leva a sério a estrutura gramatical do processo. Em sua dimensão sociolinguística ele se mostra mais do que instrumento técnico de atuação do juiz. Ele se redime desse tecnicismo dominador e excludente, quando se revela como instrumento discursivo de afirmação, proteção e restauração de direitos fundamentais da pessoa humana.

\section{REFERENCIAS}

BITTAR, Eduardo Carlos Bianca. Linguagem jurídica: semiótica, discurso e direito. $6^{\mathrm{a}}$ ed. Rev, atual. e mod. São Paulo: Saraiva, 2015.

CAPPELLETI, Mauro; GARTH, Bryant. Acesso à justiça. Tradução de Ellen Gracie Northfleet. Porto Alegre: Fabris, 1988.

CINTRA, Antonio Carlos de Araújo; GRINOVER, Ada Pellegrini; DINAMARCO, Cândido Rangel. Teoria Geral do Processo. $11^{\text {a }}$ Edição Revista e atualizada. São Paulo: Malheiros. 1995. 
DINAMARCO, Cândido Rangel, LOPES, Bruno Vasconcellos Carrilho. Teoria geral do novo processo civil. São Paulo: Malheiros, 2016.

GREIMAS, Algirdas Julien. Semiótica e Ciências sociais. Tradução de Álvaro Lorencini e Sandra Nitrini. São Paulo: Cultrix. 1976.

MARINONI, Luiz Guilherme; ARENHART, Sérgio Cruz; MITIDIERO, Daniel. Novo curso de processo civil: Teoria geral do processo. Volume $1.3^{\mathrm{a}}$ ed., rev., atual. e ampliada. São Paulo: Editora Revista dos Tribunais. 2017.

REALE, Miguel. Teoria tridimensional do direito. $5^{\text {a }}$ edição. São Paulo: Saraiva. 1994.

STRECK, Lenio Luiz. Hermenêutica jurídica e (m) Crise: uma exploração hermenêutica da construção do direito. $11^{\mathrm{a}}$ ed. rev. atual. e ampl. Porto Alegre: Livraria do Advogado Editora, 2014. 